\title{
Impact of the Effectiveness of the Internal Control System on the Reduction of Fraud in the Jordanian Public Insurance Companies
}

\author{
Ali Mustafa Magablih ${ }^{1} \&$ Ahmad Farhan Alshira' ${ }^{1}$ \\ ${ }^{1}$ Irbid National University, Jordan \\ Correspondence: Ali Mustafa Magablih, Irbid National University, Jordan. E-mail: alimagablih@yahoo.com
}

Received: January 19, 2021

Accepted: January 31, 2021

Online Published: February 5, 2021

doi:10.5539/ijbm.v16n3p84

URL: https://doi.org/10.5539/ijbm.v16n3p84

\begin{abstract}
The study aimed to figure out the effectiveness of the internal control system on the reduction of fraud in the Jordanian public insurance companies. To achieve the objectives of the study, a questionnaire was prepared and the descriptive analytical approach was adopted. The study population consisted of all the employees in the Jordanian public insurance companies under the titles (Manager / Deputy Manager, Department Manager, Head of Department, and Auditor). The study sample consisted of 168 male and female employees, and the data were analyzed using the (SPSS2) to achieve the objectives of the study.

The study concluded that there is a statistically significant impact at sig. $(\alpha \leq 0.05)$ for the dimensions of the effectiveness of the internal control system to reduce fraud.

The study recommended the need that the companies stress on acquiring the skills of successful interaction skills by the employees.
\end{abstract}

Keywords: effectiveness, internal control, the reduction of fraud, Jordanian public insurance companies

\section{Introduction}

The increasing manipulation of the accounting business has increased the pressure on the internal control jobs that focused on developing their work methods in a new way that reduces fraud and manipulation as well as giving a technical and impartial opinion on the evaluation of the financial statements. The main objective of auditing the financial statements of the enterprise is helping the auditor to express his opinion on the fairness of the financial statements and reports from all the financial aspects in accordance with a framework for evaluating the financial statements.

The effectiveness of the internal control system is an important element in the system of the corporate governance and the ability to manage the risks of response. It is also the foundation which supports the company's achievement of objectives and supporting and protecting its value. The company's organizational failure usually leads to imposing additional rules and requirements, in addition to the time and costs incurred by the company for committing to the control rules. The company's internal control provides a competitive advantage in the reduction of fraud in addition to the misleading financial data.

Moreover, the components of the internal control system are also the main method for not preparing fraudulent financial reports and they represent an important tool for management in improving the work method, improving the performance of operations and protecting funds and assets from any fraud. This makes focuses on the topics of the disclosure of the strength and effectiveness of the internal control by the Board of Directors as well as the topics of evaluating the report of the Board of Directors by the external auditor making them among the contemporary issues raised by the literature of control that are demanded by the laws of the developed countries and the practices in other countries. (Al-Qadi, 2006, p. 175)

Therefore, it is important that the management focuses on preventing distortion or manipulation, which reduces and prevents the chances of its occurrence. This includes the honesty culture and the ethical behavior. Furthermore, the administration and those entrusted in control must show this trust which is based on a set of values, namely, providing data to the individuals who use this data regarding the method of conducting work by the enterprise. (International Federation of Accountants, 2007, p. 38)

Accordingly, this study highlights the impact of the effectiveness of the internal control system on the reduction 
of fraud in the Jordanian public insurance companies.

\subsection{Study Problem and Questions}

The process of preparing an effective internal control system is one of the most important problems facing the Jordanian insurance companies, through which they aim to preserve their property, maintain the confidentiality of their work and ensure the preparation of financial reports free from fraud. Accordingly, the questions of the study problem can be summarized through the following main question:

What is the impact of the effectiveness of the internal control system on the reduction of fraud in the Jordanian public insurance companies?

This major problem has the following sub-questions:

1. What is the impact of an efficient administrative organizationalstructure on the reduction of fraud in the Jordanian public insurance companies?

2. What is the impact of the efficiency of human resources on reducing fraud in the Jordanian public insurance companies?

3. What is the impact of having and adopting sound job performance standards on the reduction of fraud in the Jordanian public insurance companies?

4. What is the impact of the quality of the accounting information system used on the reduction of fraud in the Jordanian public insurance companies?

\subsection{Study Objectives}

This study aims to determine the impact of the effectiveness of the internal control system on the reduction of fraud in the Jordanian public companies. This main objective has the following sub-objectives:

1. showing the impact of an efficient organizational structure on the reduction of fraud in the Jordanian public insurance companies.

2. Determining the impact of the availability of human resources efficiency on the reduction of fraud in the Jordanian public insurance companies.

3. showing the impact of adopting sound job performance standards on the reduction of fraud in the Jordanian public insurance companies.

4. Studying the impact of the quality of the accounting information system on the reduction of fraud in the Jordanian public insurance companies.

\subsection{Study Importance}

The importance of this study stems from the importance of the presence of effective elements for the internal control system in the reduction of fraud in the financial lists and statements in the field of control. This also includes the challenges represented in this process that are faced by the internal auditors in the Jordanian public insurance companies. This thesis will determine the ability and impact of the elements of the internal control on the reduction of fraud in the financial statements of the Jordanian public insurance companies. The importance of the study can be summarized through two aspects:

\section{First: Theoretical Aspect}

This study attempted to form an inclusive and comprehensive knowledge framework for various issues and the problem of the effectiveness of the internal control system through a scientific and logical collection of the most important variables that represent a real challenge to the internal auditors. This also includes a detailed scientific explanation of the elements of the effective internal control, and its impact on reducing fraud activities in the Jordanian public insurance companies.

\section{Second: PracticalAspect:}

With regard to this aspect of the importance of this study, a full range of factors affecting the elements of the effectiveness of the internal control system has been tested and selected through its impact on the process of the reduction of fraud activities in the Jordanian public insurance companies.

\section{Study Hypotheses:}

The study hypotheses were based on the problem of the study and its different elements. The hypotheses of the study were formulated after having real answers for the examined phenomenon studied as well as expected solutions to the problem in question. The field aspect will show the possibility of either accepting or rejecting 
them.

The main study hypothesis can be formulated as:

$\mathrm{H}$ : There is a statistically significant impact for the effectiveness of the internal control system on the reduction of fraud in the Jordanian public insurance companies.

This main hypothesis has the following sub-hypotheses:

Sub-hypothesis H1: There is a statistically significant impactfor having an efficient administrative organizational structure on the reduction of fraud in the Jordanian public insurance companies.

Sub-hypothesis H2: There is a statistically significant impactfor the availability of efficiency in the human resources on the reduction of fraud in the Jordanian public insurance companies.

Sub-hypothesis H3: there is a statistically significant impact for the adoption of sound job performance standards on the reduction of fraud in the Jordanian public insurance companies.

Sub-hypothesisH4: There is a statistically significant impact for the quality of the accounting information system used on the reduction of fraud in the Jordanian public insurance companies.

\section{Previous Studies}

There are many previous studies on varied subjects that are either directly or indirectly related to this study that are beneficial in various aspects in this stud. The studies are:

1- (Al-Jumaily, 2019) entitled: Internal institutional governance mechanisms and their impact on reducing the financial fraud in the Iraqi commercial banks

This study aimed to determine the mechanisms of the institutional governance (the Board of Directors, the Control Committee, and the internal control) and their impact on reducing the financial fraud in the Iraqi commercial banks. The researcher adopted the descriptive analytical approach, where the study was conducted on a simple random sample consisting of (10) commercial banks. (130) questionnaires were distributed to the members of the sample and there were 90 questionnaires that were subject to the study. The study concluded that there is an impact for the internal institutional governance mechanisms on reducing the financial fraud in the Iraqi commercial banks which is represented in the following mechanisms (Board of Directors, Control Committee, and Internal Control). The researcher recommended the need to work on enhancing the awareness among employees in terms of the concept of the institutional governance mechanisms and their importance, objectives and advantages of activating for reducing the different financial frauds.

2- (al-Qudah and Al-Abduallah, 2019), entitled: Commitment in applying the International Control Standard (240) of the auditor's responsibility in preventing and detecting fraud by the Jordanian external auditors

The study aimed to determine the most important methods and procedures used to detect the acts of fraud at issuing the financial statements among the public joint stock companies in Jordan in the industrial cities from the perspective of the external auditors in addition to the responsibilities held on them when detecting the fraud. The study also focused on the risk factors related to the errors in the fraudulent financial reports and the misuse of the company's assets leading to the external investigators' failure in detecting them. The study concluded that the measurement tools used in the study proved their ability to clarify the image among the external account investigators regarding the method of detecting the methods of fraud used by the companies' employees or the members of the senior management. Moreover, the study confirmed the ability of the Jordanian external auditors to discover the methods of fraud used in preparing the fraudulent financial reports. Finally, the study recommends that business organizations should be cautious in issuing the financial assets and offering shares in the markets/money in addition to credit procedures and controlling mortgages to be balanced with the real assets. The study also recommended preventing the speculative transactions and activating the role of the Jordanian financial supervisory bodies.

3- (Liu et al., 2015) entitled: "Managers Unethical Fraudulent Financial Reporting: The Impact of Control Strength and Control Framing"

This study aimed to show the effectiveness of the actual implementation of the internal control system in reducing fraud in the financial statements and the unethical behaviors using the experimental method in addition to show the methods of motivating the internal control as a means for deterring fraud. The previous studies indicated that the strength of the internal control elements reduces the fraud behavior in the financial statements. The study also aimed to show whether the effectiveness of the internal control system is conditioned only by the strength of the internal control elements, or that it depends on how the company implements the elements of the 
internal control and also reduce the possibility of engaging directors in the self-interest behaviors. The study results indicated that the strongest internal control system will lead to detect and reduce the fraudulent financial reports than the weak internal control in case the internal control technology is applied to reduce the unethical financial reporting behaviors.

\section{4- (Oyewole, \& Abiola,2012) entitled: Internal Control System on Fraud Detection: Nigeria Experience:}

The study aimed to assess whether the internal control system in Nigeria is evident in detecting fraud or not and asses the effectiveness of training employees in this regard. Ten banks were randomly selected out of 15 banks based in Lagos (Nigeria) with a participation of 200 employees of these banks and 5 managers of the selected banks. The initial data was collected through questionnaires whereas the secondary data were extracted from published bank accounts and reports. The analytical approach and the descriptive and inferentialapproach were used in analyzing data. The results showed that there is a strong and statistically significant relationship between the development of the internal control systems and the detection of fraud in the banks' annual financial reports.

\subsection{Risk Assessment}

Reducing the risks that can face institutions is one of the most important objectives of the internal control system. Such process requires determining the nature of these risks and determines the policy of the institution in dealing with them. The risks related to preparing the financial statements are one of the most important risks on which the internal control system should focus on given their negative effects on the institution's ability to prepare the financial reports (Sahen et al., 2007).

\subsection{Information and Communication System}

The information and communication systems include all the equipment and programs needed to obtain the financial evidence, preparing the financial reports and establishing the accounting records related to the company's transactions. The importance of information systems comes from the importance of information and financial reports in protecting the assets and requirements of the institution and preserving the rights of its shareholders and delivering them to the stakeholders in time as well as its role in implementing the activities of the institution (Sahen et al., 2007).

\subsection{Concept of Fraud}

Fraud in language means asking for a thing by tricks. Anyone who uses tricks, he tries it. The general meaning of fraud means a negative social phenomenon which proves that the individuals are away from adhering to moral values (Mahdi, 2011:42). There are various definitions for fraud, most important of which have been issued by specialized professional institutions, such as the Review Standards Bulletin issued by the Council of Chartered Accountants. It defined it as the deliberate misrepresentation of the financial statements. The Saudi Arabian Monetary Agency (SAMA) defined it as any practice that includes using deception to directly or indirectly obtain a form of financial benefit sought by the perpetrator (al-Fatlawi, 2009: 21). Another definition is mentioned in the International Review Standard (240) which indicates that fraud is a deliberate act by one or more individuals in the management, auditors, employees or other parties and this act includes the use of deception to obtain an unfair or illegal advantage (International Control Standard 240). This might include the irregularities in the presentation of the financial statements in which one or more board members, employees or external parties participate. Finally, the Oversight Evidence on Fraud and Corruption defined it as the deliberate falsification of important facts and information to obtain illegalfinancial benefits.

The International Control Standard (240) stated that fraud means an intentional act by one person or more in the management in addition to those entrusted with oversight, employees, or other external parties. This act is related to the use of deception for obtaining an unfair or illegal interest resulting in the misrepresentation of financial statements.

Many definitions of fraud have been mentioned, including:

1- Fraud: An act intended by one member or more from the management in addition to those entrusted with governance, employees and third parties. It contains using deception to get an unfair or illegal benefit (IFAC, 2010).

2. Definition of the Canadian Institute of Chartered Accountants (CICA.1998): Fraud refers to the acts committed with intent to deceive and they involve a misappropriation of assets or a misrepresentation of financial information in order to hide a misappropriation of assets or other purposes.

3. Fraud is also defined as deliberately concealing or modifying data for the purpose of obtaining special benefits, or misleading another party and to avoid obtaining its legitimate rights or charging it with excessive obligations, 
or obtaining the property of the economic unit to use them for special purposes (Abu Al-Rub, 2007).

From the above definitions, the researcher indicates that fraud includes:

1. Fraud is a deliberate or intentional act.

2. Fraud is committed by the employees and related persons such as management and employees.

3. Fraud distorts the financial statements.

4. Fraud is intended to obtain personal benefits.

5. Fraud causes harm to some parties, most of whom are users of the financial statements such as current and future investors and stakeholders.

\subsubsection{Types of Management Fraud}

There are two types of management fraud. The International Federation of Accountants, 2010 has provided an explanation of these types as follows:

A- Fraud resulting from a fraudulent financial report: the fraudulent financial report contains intentional misrepresentations or omissions of amounts or disclosures in the financial statements in order to cheat on the financial statements' users. The fraudulent financial report may include the following (IFAC, 2010):

1- Manipulation, forgery or modification of accounting records and therefore the issuance of fraudulent financial lists.

2- Deliberate misuse of accounting principles related to measurement, recognition, classification, presentation and disclosure.

3- Deletion of some processes or hiding important information.

(b) Fraud resulting from the theft or misuse of the assets of the enterprise: This type of fraud can occur in two ways, either from ordinary employees on a small scale or by some managers, which makes the company under risk given the fact that managers are able to hide cases of misuse of assets. It might happen in the following various methods:

1- Theft of receipts.

2. Theft of actual assets such as the theft of commodity inventory.

3- Payment for goods not received.

\subsubsection{Management's Motives of Fraud}

The increased varied research and studies on the management's motives on the topic of fraud proved that fraud exists and it is widely spread in cases of taking important decisions. The management's motives for fraud are represented in:

1- Tax Evasion

It represents the most important and main motive for fraud by companies with the blessing of the main owners and in cooperation with the external auditor.

\section{2- Achievement of Personal Gain}

The personal gains represent one of the management's most important motives for fraud in cooperation with the external auditor and at the behalf of all the related categories in the company. Sometimes, they come at the expense of the economy and society as a whole. It was evident during the current financial crisis.

\section{3- Meeting the Necessary Requirements}

The companies and their managements are committed to many legal and contractual requirements and sometimes the competitive requirements that are necessary for continuation and maintaining the market share. Achieving these requirements enables the company to maintain its customers and continue its development. Therefore, the companies use the fraud methods to meet the necessary requirements when their operation and investment conditions do not allow them to meet those requirements.

4- Obtaining or Maintaining Funding

The companies' managements often seek the funding required in various methods when they suffer from liquidity problems preventing them from continuing their operations or investments. They also seek funding to pay their obligations; therefore, they tend to refinance their expenditures and obligations through the financial institutions by resorting to the fraudulent methods to improve the outcome of the activity and the financial 
position through accounting to achieve the financing requirements imposed by the financial institutions and show the company's financial position in a way better than reality. This contributes to the relief of the investors when they notice that the company's sales are gradually increasing from a year to another resulting in maintaining the profits within what they expect. This also leads to the fact that some managers believe that the investors are focusing solely on short-term financial gains, thus they seek to adjust the profits announced through fraud.

1- External Auditor

A team of auditors state that it is impossible to detect the fraud practiced by the senior project management. In other words, if the management intentionally desired to mislead the auditor, he would not know it except by certain efforts, high cost and long time. However, the trend among the judiciary midst and financial control agencies is that the control companies must be able to detect such manipulation as it is the reason for their creation. One of the control companies in the world was able to find new methods to guide the auditor to multiple cases that may be exploited by fraud (Abdullah, 2007):

- adopting the external sources in collecting information about large transactions by a certain company. The auditor must not rely solely on the information provided to him by the management.

- Checking the many small operations related to one company cooperating with the company. The total processes represent a main indicator for the company's results.

- Accurate and careful auditing for the end dates of the financial period.

- In case of undisclosed transactions, the auditor asks the general management of the company to approve all the important transactions. However, if the members of the board of directors themselves are the managers, it is advisable for the auditor to request the intervention of the law.

- Compare the management-related transactions with similar deals made by another competitive team.

- For companies that replace their accountants from time to time or for the companies that rely on two control companies together, there must be a close cooperation between the members of the two companies to detect the rate of the management interference in the control work.

\section{2- Internal Auditor}

The internal control is responsible for preventing fraud through a test of the adequacy and effectiveness of internal controls, and detecting the weaknesses that may allow the management to cheat. Accordingly, the internal auditor must determine the following:

- The organizational environment encouraging a sense of censorship.

- Real organizational objectives.

- Company's written policies describing the expected activities.

- Devolution policies for operations.

- Channels of communication with the management through which the reliable information flows

- $\quad$ Recommendations for establishing an effective internal control system to prevent fraud.

In the researcher's view, in order to achieve positive results with regard to the financial statements' absence of fictitious numbers and to reduce the management's ability for fraud, it is important to focus on a group of parties that form the greatest pillar in achieving this. The parties include:

- External Auditor

- Internal Auditor

- Internal control

- Control Committee

These parties represent the cornerstone in reducing the management's fraud when each of these entities exercises their work honestly. The control committee is the biggest supporter of the other entities since it supervises the rest of the entities and coordinates their work. It is concerned with monitoring them and verifying the results of their work.

From the above, Abd al-Rahman (2015) summarizes the role of the internal control in reducing fraud, as follows:

1. Protecting the organization's assets from theft, damage and misuse.

2. Not using the funds of the budget allocated for this organization in addition to achieving efficiency and economy by using the allocated funds and preventing waste in using the public funds. 
3. Achieving the organization's commitment to the laws, legislation and instructions issued by the higher authorities.

4. Tracking fraud and financial and administrative abuses that can occur in the organization and reporting to the top authorities and following up on those reports so that the organization achievesits objectives.

5. Providing accurate book and record information that reflects the actual reality of the organization.

\section{Method and Procedures}

\subsection{Introduction}

This chapter includes the type of the study and the most important procedures used by the researcher to implement this study, which include determining the study population, the methods used in data collection and the most important statistical methods through which data were analyzed and the method of reaching to the results.

\subsection{Study Methodology}

This study is one of the causal explanatory studies where the researcher adopted the descriptive analytical approach that depends on studying the phenomenon as it is in fact and accurately. This is followed by an analysis of the correlation relations and the causality found between the independent variable represented in the effectiveness of the internal control system, and the dependent variable that was represented in the reduction of fraud in an attempt to figure out the impact of the independent variable on the dependent variable to reach to conclusions that contribute to the development and improvement of reality.

\subsection{Study Population}

The study population consisted of all the employees in the Jordanian public insurance companies under the titles (Manager/ Deputy Manager, Department Manager, Head of Department, and Auditor).

\subsubsection{Study Sample}

The study sample consisted of 168 male and female employees in the Jordanian public insurance companies under the titles (Manager / Deputy Manager, Department Manager, Head of Department, and Auditor) where the researcher distributed 185 questionnaires out of which 168 were recovered.

\subsubsection{Data Collection Sources}

The researcher adopted two main sources for data collection that are represented in:

Secondary Sources: These sources consisted of books and periodicals related to the subject of the study as well as the online data on the subject.

Primary Sources: For obtaining the data needed to reach to the required results of the study, a questionnaire related to the subject of the study and $\mathrm{MA}$ and $\mathrm{PhD}$ theses were prepared after adopting the theoretical framework for the study and the previous studies presented above.

\subsubsection{Study Tool}

The questionnaire consisted of three parts (annex No.). The first part included the demographic data (personal and functional information) related to the members of the study sample, represented in: qualification, experience, career status and professional certificates.

The second part of the questionnaire consisted of 40 items reflecting the study sample assessment of level of the independent variable, the effectiveness of the internal control system, which consists of the following sub-dimensions:

- The first dimension: the existence of an efficient administrative organizational structure through (10) items.

- The second dimension: the availability of efficiency in human resources through (10) items.

- The third dimension: the existence and adoption of sound standards of functional performance through (10) items. 
Table 1. The fourth dimension: the quality of the accounting information system adopted through (10) items

\begin{tabular}{|c|c|c|c|}
\hline \multirow{2}{*}{ Field } & \multirow{2}{*}{ Dimension } & (Cronbach's & \multirow[t]{9}{*}{ Alpha) } \\
\hline & & Coefficient & \\
\hline \multirow{5}{*}{ effectiveness of internal control } & existence of an efficient administrative organizational structure & 0.79 & \\
\hline & Availability of human resources efficiency & 0.86 & \\
\hline & existence and adoption of sound job performance standards & 0.80 & \\
\hline & Quality of accounting information system & 0.73 & \\
\hline & field of the effectiveness of the internal control system as a whole & 0.89 & \\
\hline Fraud Reduction Area & & 0.88 & \\
\hline tool as a whole & & 0.89 & \\
\hline
\end{tabular}

\subsection{Reliability of Study Tool}

The Cronbach's Alpha coefficient was used to verify the internal consistency of the questionnaire items as a whole given the fact that it is the most common scale used to achieve this purpose. The results are shown in the table below, which shows that the Cronbach's Alpha coefficient as a whole was $(0.941$. most studies indicate that the acceptance rate for the reliability coefficient is (0.70) (al-Najjar \& al-zoubi, 2013).

Reliability coefficients (Cronbach's Alpha) for all the items of the study dimensions and the tool as a whole

It is clear from the previous table that the values of the Cronbach's alpha coefficients for all the dimensions and areas of study were high where many specialists find that the test for judging the adequacy of the Cronbach's Alpha coefficient is $(0.60)$ (al-Sharifin \& al-Kilani, 2007) which indicates the reliability of the results that the study tool can produce when applied.

\subsection{Statistical Methods}

To achieve the objectives of the study and analyze the data collected, the researcher encoded and computerized the data through the SPSS. The researcher also used many appropriate statistical methods in this program, which are the following:

1- Frequency: it was used to describe the characteristics of the study sample, figure out its items and prepare the members to which the study tool was distributed.

2- Percent: it was used to identify the rate of repetitions in relation to the description of the characteristics of the study sample.

3. Mean: it was used to calculate the average answer for each of the questionnaire item in addition to the mean of each dimension of the study.

4- Standard Deviation: it was used to determine the extent to which the readings are away from the center of their aggregation for each item of the study tool.

5- The multiple regression coefficients: it was used to test the validity of the hypotheses related to the impact of the independent variable on the dependent variable.

\subsection{Statistical Analysis and Hypotheses Testing}

\subsubsection{Introduction}

This chapter includes the presentation and discussion of the researcher's findings in light of the following steps, which were followed to verify the validity of the research assumptions. They aimed to figure out the effectiveness of the internal control system in reducing fraud in the public insurance companies in Jordan. Here are the results:

\subsubsection{Demographic Characteristics of the Study Sample}

The research sample included male and female employees in the Jordanian service companies who were divided according to the study demographic variables (scientific qualification, years of experience, career status, and professional certificates). This is evident through the following tables:

\section{1- Scientific Qualification}


Table 2. Distribution of the research sample according to the scientific qualification variable $(\mathrm{n}=336)$

\begin{tabular}{llll}
\hline Variable & level & frequency & Percent \\
\hline & diploma & 26 & 15.5 \\
Qualification & $\mathrm{BA}$ & 133 & 79.2 \\
& $\mathrm{MA}$ & 7 & 4.2 \\
& $\mathrm{PhD}$ & 2 & 1.2 \\
& total & 168 & 100.0 \\
\hline
\end{tabular}

Table 2 shows the distribution of the research sample according to the qualification where the highest percent of the distribution of the study sample members according to the scientific qualification was (79.2\%) for the (BA) while the lowest percent (1.2\%) was for the (Ph.D.). This shows that the highest practical qualifications among the members of the study sample were (B.B.) and the lowest were (Ph.D.) which is attributed to the fact that the members of this community focus more on professional certificates than academic certificates, which confirms the validity of the responses of the sample members.

2- Number of Years of Experience

Table 3. Distribution of the research sample according to the variable of years of experience

\begin{tabular}{llll}
\hline Variable & level & frequency & Percent \\
\hline & Less than 5 years & 15 & 8.6 \\
& From 5 years to less than 10 years & 52 & 31.3 \\
Number of years of experience & From 11 years to less than 15 years & 66 & 39.3 \\
& 15 years and above & 35 & 20.8 \\
& total & 168 & 100.0 \\
\hline
\end{tabular}

The table shows the distribution of the research sample members according to the variable of the number of years of experience where the highest percent for the distribution of the study sample members according to the variable of the number of years of experience was (39.3\%) for (from 11 years to less than 15 years), while the lowest percent was $(8.6 \%)$ for (less than 5 years). The researcher attributes the high rate of experience (from 11 years to less than 15 years), which is considered medium in the field of control, to the fact that most of those who go to work in the field of control have previously worked in the field of accounting and have gained an accounting experience then they work in the field of control. therefore, their experience in the field of control is medium.

3- Job Status

Table 4. Distribution of the research sample according to the specialty variable

\begin{tabular}{llll}
\hline Variable & Level & frequency & Percent \\
\hline \multirow{4}{*}{ Job status } & Manager/Deputy- Manager & 7 & 3.9 \\
& Department Manager & 33 & 19.9 \\
& Head of Section & 51 & 30.7 \\
& Auditor & 77 & 45.5 \\
& Total & 168 & 100.0 \\
\hline
\end{tabular}

The table shows the distribution of the members of the research sample according to the variable of specialty where the highest percent of the distribution of the study sample members according to the specialty variable was $(45.5 \%)$ for (auditor), while the lowest percent was $(3.9 \%)$. The researcher attributes this to the nature of the career levels in the companies examined.

\subsection{Descriptive Results of the Independent Variable "Internal Control System Effectiveness"}

This part of the fourth chapter aims to identify the level of the effectiveness of the internal control system in the Jordanian public service companies by extracting the means and standard deviations of the respondents' answers 
to the dimensions of the independent variable "internal control effectiveness".

Table 5. Means and standard deviations of the answers of the study sample members regarding the independent variable dimensions of the "internal control system effectiveness" in a descending order according to the mean

\begin{tabular}{|c|c|c|c|c|c|}
\hline Rank & Number & dimension & mean & $\begin{array}{l}\text { Standard } \\
\text { Deviation }\end{array}$ & $\begin{array}{l}\text { Assessmen } \\
\text { Level }\end{array}$ \\
\hline 1 & 1 & Existence of an efficient administrative organizational structure & 3.87 & 0.14 & High \\
\hline 2 & 4 & quality of the accounting information system adopted & 3.74 & 0.23 & High \\
\hline 3 & 3 & existence and adoption of sound job performance standards & 3.73 & 0.17 & High \\
\hline 4 & 2 & Availability of Human Resources Efficiency & 3.71 & 0.20 & High \\
\hline \multicolumn{3}{|c|}{ effectiveness of the internal control system as a whole } & 3.76 & 0.14 & High \\
\hline
\end{tabular}

The table shows that the level of the effectiveness of the internal control system in the Jordanian service companies was high, as the mean of the respondents' answers to the field of the effectiveness of the internal control system as a whole was (3.76) by a high assessment level. The table also shows that the means for the answers of the members of the study sample on the dimensions of the effectiveness of the internal control system ranged from (3.71-3.87) with a high assessment for all the dimensions of the field. The dimension "the existence of an efficient administrative organizational structure" was ranked first with a mean of (3.87), the dimension of "the quality of the accounting information system adopted" was ranked second by a mean of (3.74), the dimension "existence and adoption of sound job performance standards" was ranked third by a mean of (3.73), and finally the dimension of the "availability of human resources efficiency" was ranked fourth and last by a mean of (3.71).

To determine the level of the effectiveness of the internal control system in details, the researcher extracted the means and standard deviations of the answers of the study sample members regarding the items of each dimension of the internal control system separately. Here are the results:

The first dimension: an efficient administrative organizational structure.

Table 6. Means and standard deviations of the answers of the study sample members regarding the items of the existence of an efficient administrative organizational structure in a descending order according to the mean

\begin{tabular}{|c|c|c|c|c|c|}
\hline Rank & Number & dimension & mean & Standard Deviation & Assessment Level \\
\hline 1 & 1 & $\begin{array}{l}\text { There is a separation between the job and the person who } \\
\text { occupies it. }\end{array}$ & 4.74 & 0.48 & High \\
\hline 2 & 3 & $\begin{array}{l}\text { The organizational structure is adaptable to the } \\
\text { unexpected variables }\end{array}$ & 4.64 & 0.54 & High \\
\hline 3 & 9 & $\begin{array}{l}\text { The organizational structure covers all the company's } \\
\text { functions and tasks. }\end{array}$ & 4.63 & 0.57 & high \\
\hline 4 & 6 & $\begin{array}{l}\text { Lines of communication and relationships among the } \\
\text { activity departments in the organizational structure of the } \\
\text { company are clear }\end{array}$ & 4.57 & 0.63 & High \\
\hline 5 & 5 & $\begin{array}{l}\text { The authorities and responsibilities are determined at the } \\
\text { level of each activity in the organizational structure }\end{array}$ & 3.49 & 0.64 & medium \\
\hline 6 & 10 & $\begin{array}{l}\text { The organizational structure suffers from a lack of } \\
\text { continuous development and it takes the traditional form. }\end{array}$ & 3.41 & 0.55 & medium \\
\hline 7 & 7 & $\begin{array}{l}\text { The organizational structure clearly shows the control } \\
\text { functions of the Internal Control department }\end{array}$ & 3.35 & 0.54 & medium \\
\hline 8 & 8 & $\begin{array}{l}\text { the Internal Control department is linked to the highest } \\
\text { level within the organizational structure }\end{array}$ & 3.32 & 0.52 & medium \\
\hline 9 & 4 & $\begin{array}{l}\text { The organizational structure has the potential to be } \\
\text { modified in a short time without the need for substantial } \\
\text { adjustments. }\end{array}$ & 3.29 & 0.49 & medium \\
\hline 10 & 2 & The organizational structure is adaptable to meet changes & 3.26 & 0.48 & medium \\
\hline \multicolumn{3}{|c|}{$\begin{array}{l}\text { Dimension of the existence of an efficient administrative organizational structure } \\
\text { as a whole }\end{array}$} & 3.87 & 0.14 & High \\
\hline
\end{tabular}


The table shows that the means of the answers of the study sample members to the dimension "having an efficient administrative organizational structure" ranged from (4.63-3.26) where the first rank was for item 1: "there is a separation between the job and the person who occupies it" by a mean of (4.63) by a high assessment level, while the last rank was for item 2: "the organizational structure is adaptable to meet changes" with a mean of (3.26) and a medium assessment level. The mean for the dimension as a whole was (3.87) by a medium assessment level.

The second dimension: the availability of efficiency in human resources.

Table 7. Means and standard deviations of the answers of the study sample members regarding the items of the existence of human resources efficiency in a descending order according to the mean

\begin{tabular}{|c|c|c|c|c|c|}
\hline Rank & Number & dimension & mean & $\begin{array}{l}\text { Standard } \\
\text { Deviation }\end{array}$ & Assessment Level \\
\hline 1 & 9 & $\begin{array}{l}\text { Employees of the company have the skills that distinguish them } \\
\text { from their counterparts in other companies. }\end{array}$ & 4 & 0.57 & High \\
\hline 2 & 3 & $\begin{array}{l}\text { the employees apply the knowledge they acquire from different } \\
\text { sources at work. }\end{array}$ & 4.54 & 0.64 & High \\
\hline 3 & 7 & $\begin{array}{l}\text { The practical skills of employees are in line with the company's } \\
\text { work requirements. }\end{array}$ & 4.31 & 0.80 & High \\
\hline 4 & 6 & $\begin{array}{l}\text { Employees have the right technical skills to get the job done } \\
\text { properly. }\end{array}$ & 3.61 & 0.70 & medium \\
\hline 5 & 5 & $\begin{array}{l}\text { The company's employees with supervisory positions have the } \\
\text { right knowledge to work. }\end{array}$ & 3.36 & 0.60 & medium \\
\hline 5 & 10 & $\begin{array}{l}\text { there are technical courses to be passed to develop the } \\
\text { capabilities of the internal auditors }\end{array}$ & 3.36 & 0.56 & medium \\
\hline 7 & 1 & $\begin{array}{l}\text { Employees have the technical knowledge to complete the } \\
\text { required work perfectly. }\end{array}$ & 3.34 & 0.50 & medium \\
\hline 8 & 2 & $\begin{array}{l}\text { The supervisory functions are assigned to the internal observers } \\
\text { according to the nature of their qualifications, professionalism } \\
\text { and competences }\end{array}$ & 3.33 & 0.53 & medium \\
\hline 8 & 4 & $\begin{array}{l}\text { The qualifications needed to carry out the internal control work } \\
\text { are determined with the required efficiency. }\end{array}$ & 3.32 & 0.67 & medium \\
\hline 10 & 8 & $\begin{array}{l}\text { The company's employees have the skills to interact with others } \\
\text { successfully. }\end{array}$ & 3.31 & 0.55 & medium \\
\hline \multicolumn{3}{|c|}{ Dimension of the availability of the efficiency in the human resources as a whole } & 3.71 & 0.20 & High \\
\hline
\end{tabular}

The table shows that the means for the answers of the study sample members for the dimension "availability of human resources efficiency" ranged from (4.64-3.31) where item 9, which stated: "employees of the company have the skills that distinguish them from their counterparts in other companies" was ranked first by a mean of (4.64) and a high assessment level. However, item 8, which stated, "the company's employees have the skills to interact with others successfully" was ranked last with a mean of (3.31) and a medium assessment level. The mean for the dimension as a whole was (3.71) with a high assessment level.

The third dimension: the existence and adoption of sound standards of job performance. 
Table 8. Means and standard deviations of the answers of the study sample members regarding the items of the existence and adoption of sound performance standards for the job performance in a descending order according to the mean

\begin{tabular}{|c|c|c|c|c|c|}
\hline Rank & Number & dimension & mean & $\begin{array}{l}\text { Standard } \\
\text { Deviation }\end{array}$ & $\begin{array}{l}\text { Assessment } \\
\text { Level }\end{array}$ \\
\hline 1 & 6 & $\begin{array}{l}\text { The internal control activities include the control of the risk } \\
\text { management approach to ensure its effectiveness. }\end{array}$ & 4.68 & 0.54 & High \\
\hline 2 & 9 & $\begin{array}{l}\text { The internal control process includes implementing the procedures } \\
\text { and activities to ensure that the operations carried out are consistent } \\
\text { with the financial and legal regulations. }\end{array}$ & 4.59 & 0.56 & High \\
\hline 3 & 1 & $\begin{array}{l}\text { the internal Auditors' reports are reviewed to figure out the deviations } \\
\text { and irregularities that occur in each period. }\end{array}$ & 4.56 & 0.66 & High \\
\hline 4 & 2 & $\begin{array}{l}\text { The reports of the bodies related to the company's activity are } \\
\text { examined and reviewed and their observations are analyzed. }\end{array}$ & 3.45 & 0.64 & medium \\
\hline 5 & 3 & $\begin{array}{l}\text { The external auditor's report, observations and reservations, if any, are } \\
\text { examined. }\end{array}$ & 3.40 & 0.57 & medium \\
\hline 6 & 10 & the control activities include quality control procedures. & 3.36 & 0.60 & medium \\
\hline 7 & 7 & $\begin{array}{l}\text { control procedures are imposed on the financial reporting process to } \\
\text { ensure its reliability. }\end{array}$ & 3.33 & 0.58 & medium \\
\hline 8 & 5 & $\begin{array}{l}\text { Policies and procedures are followed to provide a reasonable } \\
\text { assurance regarding the internal control objectives. }\end{array}$ & 3.32 & 0.52 & medium \\
\hline 9 & 8 & $\begin{array}{l}\text { The financial ratios necessary for linking and comparing the results of } \\
\text { the control examinations are analyzed and extracted. }\end{array}$ & 3.31 & 0.52 & medium \\
\hline 10 & 4 & $\begin{array}{l}\text { the customers' feedback, comments and complaints on their financial } \\
\text { and non-financial matters are followed up. }\end{array}$ & 3.29 & 0.48 & medium \\
\hline \multicolumn{3}{|c|}{$\begin{array}{l}\text { Dimension of the existence and adoption of sound performance standards for the job } \\
\text { performance as a whole }\end{array}$} & 3.73 & 0.17 & High \\
\hline
\end{tabular}

The table shows that the means for the answers of the study sample regarding the dimension of "the existence and adoption of sound standards for the job performance" ranged from (4.68-3.29) where item 6, "the internal control activities include the control of the risk management approach to ensure its effectiveness" was ranked first by a mean of 4.68 and a high assessment level. However, item (4), "the customers' feedback, comments and complaints on their financial and non-financial matters are followed up" was ranked second with a mean of (3.29) and a medium assessment level. The mean for the dimension as a whole was (3.73) by a high assessment level.

The fourth dimension: the quality of the accounting information system followed.

Table 9. Means and standard deviations of the answers of the study sample members regarding the items of the dimension of the quality of the accounting information system adopted in a descending order according to the mean

\begin{tabular}{|c|c|c|c|c|c|}
\hline Rank & Number & dimension & mean & $\begin{array}{l}\text { Standard } \\
\text { Deviation }\end{array}$ & $\begin{array}{l}\text { Assessment } \\
\text { Level }\end{array}$ \\
\hline 1 & 1 & $\begin{array}{l}\text { The related accounting information is determined in order to subject it to the } \\
\text { internal control checks. }\end{array}$ & 4.70 & 0.50 & High \\
\hline 2 & 7 & $\begin{array}{l}\text { The accounting information system provides information for the financial } \\
\text { operations to link them and to ensure determining their assets. }\end{array}$ & 4.46 & 0.76 & High \\
\hline 3 & 9 & $\begin{array}{l}\text { The accounting information system provides open channels of } \\
\text { communication between the internal control department and the senior } \\
\text { management that allow reporting on officials' irregularities. }\end{array}$ & 4.45 & 0.66 & High \\
\hline 4 & 3 & $\begin{array}{l}\text { The accounting information system provides the possibility of issuing } \\
\text { impartial financial reports with no bias. }\end{array}$ & 3.56 & 0.62 & medium \\
\hline 5 & 8 & $\begin{array}{l}\text { The accounting information system provides the possibility of verifying the } \\
\text { authenticity of the documentary cycle and the flow of information among } \\
\text { sections according to activities in order to ensure the correct registration of }\end{array}$ & 3.51 & 0.66 & medium \\
\hline
\end{tabular}




\begin{tabular}{|c|c|c|c|c|c|}
\hline Rank & Number & dimension & mean & $\begin{array}{l}\text { Standard } \\
\text { Deviation }\end{array}$ & $\begin{array}{l}\text { Assessment } \\
\text { Level }\end{array}$ \\
\hline & & operations & & & \\
\hline 6 & 6 & $\begin{array}{l}\text { The accounting information system provides the ability to ensure that the } \\
\text { company's financial operations are identified, compiled, classified, analyzed } \\
\text { and reported so as to be controlled. }\end{array}$ & 3.40 & 0.71 & medium \\
\hline 7 & 2 & $\begin{array}{l}\text { There is an appropriate accounting information system that allows the } \\
\text { information to be checked so as the internal control department can get what } \\
\text { it needs to carry out its activities. }\end{array}$ & 3.36 & 0.61 & medium \\
\hline 8 & 4 & $\begin{array}{l}\text { The Accounting Information System provides reports characterized by } \\
\text { honest representation of events to be proven. }\end{array}$ & 3.33 & 0.54 & medium \\
\hline 9 & 5 & $\begin{array}{l}\text { The accounting information system used provides additional information to } \\
\text { the beneficiary. }\end{array}$ & 3.32 & 0.69 & medium \\
\hline 10 & 10 & $\begin{array}{l}\text { The accounting information system provides feedback in a way that helps } \\
\text { determine and change the current forecasts and assess the results of previous } \\
\text { decisions. }\end{array}$ & 3.29 & 0.49 & medium \\
\hline \multicolumn{3}{|c|}{ Dimension of the quality of the accounting information system adopted as a whole } & 3.74 & 0.23 & High \\
\hline
\end{tabular}

The table shows that the means of the answers of the study sample members for the dimension of "the quality of the accounting information system adopted" ranged from (4.70-3.29) where the first place was for item (1), "the related accounting information is determined in order to subject it to the internal control checks", with a meanof (4.70) and a high assessment level, while the last place was for item (10), "the accounting information system provides feedback in a way that helps determine and change the current forecasts and assess the results of previous decisions", with a mean of 3.29 and a medium assessment level. The mean for the dimension as a whole was (3.74) at a high assessment level.

\subsection{Descriptive results for the dependent variable of "Reducing Fraud"}

This section aims to determine the level of the fraud reduction in the Jordanian public service companies by extracting the means and standard deviations for the answers of the study sample regarding the items of the fraud reduction.

Table 10. Means and standard deviations of the answers of the study sample members regarding the items of the fraud reduction field in a descending order according to the mean

\begin{tabular}{|c|c|c|c|c|c|}
\hline Rank & Number & dimension & mean & $\begin{array}{l}\text { Standard } \\
\text { Deviation }\end{array}$ & $\begin{array}{l}\text { Assessment } \\
\text { Level }\end{array}$ \\
\hline 1 & 1 & $\begin{array}{l}\text { There is a search for possibilities of management's irregularities } \\
\text { or improper use of control. }\end{array}$ & 4.71 & 0.52 & High \\
\hline 2 & 5 & $\begin{array}{l}\text { Quarter analyses of key reserves are carried out to ensure that } \\
\text { there are no irregularities. }\end{array}$ & 4.58 & 0.62 & High \\
\hline 3 & 6 & $\begin{array}{l}\text { The control procedures for fraud screening are studied and } \\
\text { assessed in addition to examining the reports of the internal } \\
\text { auditor. }\end{array}$ & 4.53 & 0.68 & High \\
\hline 4 & 4 & $\begin{array}{l}\text { A comparison is made between the reasonableness of the } \\
\text { financial results and the previous or expected financial results. }\end{array}$ & 3.35 & 0.56 & medium \\
\hline 5 & 2 & $\begin{array}{l}\text { Management processes and procedures are assessed and } \\
\text { documented for all the important estimates used in the financial } \\
\text { reporting process. }\end{array}$ & 3.30 & 0.52 & medium \\
\hline 6 & 3 & $\begin{array}{l}\text { The fight against fraud in the financial disclosures is taken into } \\
\text { account to solve the problems of the company's stakeholders by } \\
\text { ensuring and protecting shareholders' rights. }\end{array}$ & 3.26 & 0.49 & medium \\
\hline \multicolumn{3}{|c|}{ fraud reduction field as a whole } & 3.95 & 0.20 & High \\
\hline
\end{tabular}


The table shows that the level of the reduction of fraud in the Jordanian public service companies was high since the mean of the respondents' responses to the fraud reduction as a whole was (3.95) by a high assessment level. The table also shows that the means of the respondents of the study sample on the fraud reduction items ranged from (3.26-4.71). item (1), "there is a search for possibilities of management's irregularities or improper use of control" was ranked first with a mean of (4.71) and a high assessmentlevel, while item (3) stating "the fight against fraud in the financial disclosures is taken into account to solve the problems of the company's stakeholders by ensuring and protecting shareholders' rights" was ranked last by a mean of (3.26) and a medium assessment level."

\subsection{Testing the Study Hypotheses}

The methods of the inferential statistics were used to test the hypotheses. To validate the objectivity of the study results, a (Kolmogorov Smirnov Test) was conducted to confirm that the data are free of the statistical problems that might negatively affect the results of testing the study hypotheses. This test requires the availability of the normal distribution in the data. On the contrary, a false correlation arises between the study dependent variables and independent variables. Thus, the correlation loses its ability to explain or predict the phenomenon in question, as shown in the table.

Table 11. Normal distribution of the dimensions of the independent and dependent variable

\begin{tabular}{llll}
\hline Field & Dimension & Kolmogorov - Smirnov & Result \\
& Existence of an efficient administrative organizational structure & 1.02 & normal distribution \\
& Availability of Human Resources Efficiency & 1.00 & normal distribution \\
Internal control & existence and adoption of sound performance standards & 1.02 & normal distribution \\
& quality of the accounting information system adopted & 1.07 & normal distribution \\
\hline
\end{tabular}

Note. * The distribution is normal when it is at sig. $(\alpha \leq 0.05)$.

Looking at the table, we find that the distribution of all the variables was normal where the normal distribution of all the answers was greater than (0.05), which is the level used in the statistical treatment of this study.

Before starting testing the hypotheses, the researcher diagnosed the problem of the internal correlations of the independent variables through adopting the tolerance factor (Tolerance) for each of the independent variables as well as the (Variance Inflation Factor: VIF) where the values of the VIF should be less than (10) for all the independent variables and the (Tolerance) values should be greater than (0.05). Table 14-4 explains this.

Table 12. Testing the variance inflation factor (VIF) and the tolerance for the dimensions of the independent variable

\begin{tabular}{lll}
\hline Dimension & tolerance & Variance Inflation Factor (VIF) \\
\hline existence of an efficient administrative organizational structure & 0.72 & 1.39 \\
Availability of human resources efficiency & 0.36 & 2.81 \\
existence and adoption of sound job performance standards & 0.43 & 2.30 \\
Quality of accounting information system & 0.73 & 1.37 \\
\hline
\end{tabular}

The table shows that the test values of the VIF for all the dimensions of the independent variable were less than (10), while the tolerance test value for all the dimensions was greater than $(0.05)$. This means that there is no high correlation among the dimensions of the independent variable. therefore, we can use all of them in the regression model, determine if any of the dimensions has a statistically significant impact on the dependent variable, and figure out the percent of that impact, if any. After ensuring that there is no high correlation among the dimensions of the independent variable, the study hypotheses will be tested as described below:

Main Hypothesis: H: There is a statistically significant impact at sig. $(\alpha \leq 0.05)$ for the effectiveness of the internal control system on the reduction of fraud in the Jordanian public insurance companies.

This main hypothesis has the following sub-hypotheses:

Sub-Hypothesis: H1: There is a statistically significant impact at sig. $(\alpha \leq 0.05)$ for the presence of an efficient 
administrative organizational structure on the reduction of fraud in the Jordanian public insurance companies.

Sub-hypothesis: H2: There is a statistically significant impactat sig. $(\alpha \leq 0.05)$ for the efficiency in the human resources on the reduction of fraud in the Jordanian public insurance companies.

Sub-hypothesis H3: There is a statistically significant impactat sig. $(\alpha \leq 0.05)$ for the existence and adoption of sound job performance standards on the reduction of fraud in the Jordanian public insurance companies.

Sub-hypothesis:H4: there is a statistically significant impact at sig. $(\alpha \leq 0.05)$ for the quality of the accounting information system used on the reduction of fraud in the Jordanian public insurance companies.

Table 13. Results of applying the multiple regression equation to study the impact of the dimensions of the effectiveness of the internal control system on the reduction of fraud in the Jordanian public service companies

\begin{tabular}{|c|c|c|c|c|c|c|c|}
\hline Dimension & $\mathbf{B}$ & $\mathbf{T}$ & $\begin{array}{l}\text { Statistical } \\
\text { significance }\end{array}$ & $\mathbf{R}$ & $\mathbf{R}^{2}$ & $\mathbf{F}$ & $\begin{array}{l}\text { Statistical } \\
\text { significance }\end{array}$ \\
\hline $\begin{array}{l}\text { existence of an efficient administrative } \\
\text { organizational structure }\end{array}$ & 0.16 & 5.52 & 0.00 & \multirow{4}{*}{0.89} & \multirow{4}{*}{0.80} & \multirow{4}{*}{335.46} & \multirow{4}{*}{0.00} \\
\hline Availability of human resources efficiency & 0.29 & 6.98 & 0.00 & & & & \\
\hline $\begin{array}{l}\text { existence and adoption of sound job performance } \\
\text { standards }\end{array}$ & 0.63 & 17.09 & 0.00 & & & & \\
\hline Quality of accounting information system & 0.11 & 3.89 & 0.00 & & & & \\
\hline
\end{tabular}

The table shows:

1- Results related to the main hypothesis: there is a statistically significant impact at sig. $(\alpha \leq 0.05)$ for the dimensions of the effectiveness of the internal control system on the reduction of fraud. The value of the correlation coefficient $(\mathrm{R})$ was $(0.89)$ which is a statistically significant value indicating a statistically significant correlation between the independent variables and the dependent variables. The value of the (R-square) was $(0.80)$ which is a statistically significant value that explains the effectiveness of the internal control system in the reduction of fraud in the Jordanian public service companies. This means that the value of the dimensions of the effectiveness of the internal control system was $(80 \%)$ of the change in the reduction of fraud. As for the value of the test (F), it was (335.46) by a statistical significance of (0.00), which is a statistically significant value indicating a variance in the ability of the independent variables to influence the dependent variable. So, the first major hypothesis is accepted.

2. Results related to the first sub-hypothesis: there is a statistically significant impact at sig. $(\alpha \leq 0.05)$ for the existence of an efficient administrative organizational structure on the reduction of the fraud in the Jordanian public companies, where the values of $(B, T)$ were $(0.16,5.52)$, which were statistically significant.

3- Results related to the second sub-hypothesis: there is a statistically significant impact at sig. $(\alpha \leq 0.05)$ for the availability of efficiency in human resources on the reduction of fraud in the Jordanian public companies, where the values of $(B, T)$ were $(0.29,6.98)$ which are statistically significant.

4- Results related to the third sub-hypothesis: there is a statistically significant impact at sig. $(\alpha \leq 0.05)$ for the existence and adoption of sound job performance standards on the reduction of fraud in the Jordanian public companies, where the values of $(B, T)$ were $(0.63,17.09)$ which are statistically significant.

5- Results related to the fourth sub-hypothesis: there is a statistically significant impact at sig. $(\alpha \leq 0.05)$ for the quality of the accounting information system used to reduce the fraud in the Jordanian public companies, where the values of $(ß, T)$ were $(0.11,3.89)$ which are statistically significant.

\section{Discussion of Results and Recommendations}

This chapter discusses the results of the current study, which aimed to determine the impact of the internal control system on the reduction of fraud in the Jordanian public insurance companies, as follows:

\subsection{Discussion of Results}

The results showed a statistically significant impact at sig. $(\alpha \leq 0.05)$ for the dimensions of the effectiveness of the internal control system on the reduction of fraud. This is attributed to the fact that most companies seek to protect their assets and investments from the possibilities of fraud through adopting an accurate and structured 
database. Furthermore, the attention in the internal control increased given its importance and impact in ensuring the achievement of objectives conducted by the managements as well as assessing and following up the plan, study the causes preventing reaching the goal, assess the results of the businesses to the results targeted and achieve the maximum productivity possible by eliminating the extravagance of all activities. The control profession requires conducting three basic steps that can be used in any area of monitoring funds and activities: setting the standards, measuring the performance, and correcting the deviations. Other sub- results for the hypotheses include:

1. There is a statistically significant impact at sig. $(\alpha \leq 0.05)$ for the presence of an efficient administrative organizational structure on the reduction of fraud in the Jordanian public companies. This is attributed to the fact that such efficient organizational structure is considered the core of the control process indicating the structure that determines the different responsibilities and authorities of all the departments and persons accurately and clearly. It also applies the principle of separation of different tasks, which helps in the company's ability to reduce the fraud.

2. There is a statistically significant impact at sig. $(\alpha \leq 0.05)$ for the availability of the efficiency in the human resources on the reduction of the fraud in the Jordanian public companies. This can be attributed to the adoption of a sound policy in selecting the new employees or promoting the existing employees and the preparation of training programs for the employees to develop their competencies and practical skills. The presence of highly qualified, capable and confident employees is considered a crucial factor for the success of the internal control either in the case of weak controls or high controls, which contributes to the reduction of fraud.

3. There is a statistically significant impact at sig. $(\alpha \leq 0.05)$ for the existence and adoption of sound performance standards on the reduction of fraud in the Jordanian public companies. This can be attributed to the fact that setting the standard to the model or performance desired to be achieved represents the selected points of the total plan which measures the performance and gives the signals that explain to them the method of how matters are conducted without the need to control and supervise each step in implementing plans. The management also needs to set performance standards for all the activities conducted in the project. The standards may be expressed in terms such as product quality, earned profits and accrued expenses. The standards can be divided into two types, reflecting on the reduction of fraud.

4. There is a statistically significant impact at sig. $(\alpha \leq 0.05)$ for the quality of the accounting information system used to reduce the fraud in the Jordanian public companies. This is attributed to the fact that the high quality of the information system contributes to the availability of appropriate information and communications at the appropriate time which is also considered a main element in the effectiveness of the internal control. The appropriateness of the information system is determined by the reports sent from the system to the management. As for the communications, the control of the financial reports requires reporting duties to the employees in the organization regarding the procedures of the internal control procedures clearly which contributes to increasing the company's ability to reduce fraud.

\subsection{Recommendations}

In light of studying the impact of the effectiveness of the internal control system on the reduction of fraud in the Jordanian public insurance companies and the researcher's results of what was presented in the theoretical aspect or analyzed in the scientific aspect, the researcher recommends the following:

1. Companies should be concerned about the level of the flexibility of its organizational structure due to the easiness of conducting changes in a short time without the need for substantial changes.

2. the service companies should be concerned about the possibility of organization in the organizational structure of the adaptation to meet the changes.

3.the service companies should seek to appoint employees with the skills of interacting successfully with others.

4.the service companies should follow up the customers' feedback, comments and complaints about their financial and non-financial matters.

5. providing an accounting information system with a high level of feedback in a way that helps determine and the current expectations as well as assess the results of the previous decisions.

\section{References}

Abd, A. R., \& Amir, H. (2015). The role of the effectiveness of the internal control in the reduction of the financial and administrative abuses in the Iraqi public universities. MA thesis, Al al-Bayt University, Jordan. 
Abu, A. R., \& Moath, A. A. K. (2007). The extent of applying the international audit standard 240 on the auditor's responsibility to detect and prevent fraud by the Palestinian auditors. Unpublished MA thesis, Yarmouk University, Irbid, Jordan.

Al-Fatlawi, A. S. B. (2009). The role of the auditor in detecting the fraud in the financial data, Certificate of Legal Accounting, Arab Institute of Chartered Accountants, Baghdad.

Al-Jumaily, T. J. S. (2019). The mechanisms of the Internal institutional governance and their impact on the reduction of the financial fraud in the Iraqi commercial banks. MA Thesis, Al-Bayt University.

Mahdi, H. A. (2011). Quality of Audit and Its Implications in Fighting Corruption, Certificate of Legal Accounting, Arab Institute of Chartered Accountants, Baghdad.

\section{Copyrights}

Copyright for this article is retained by the author(s), with first publication rights granted to the journal.

This is an open-access article distributed under the terms and conditions of the Creative Commons Attribution license (http://creativecommons.org/licenses/by/4.0/). 